\title{
Pericardial closure with extracellular matrix scaffold following cardiac surgery associated with a reduction of postoperative complications and 30-day hospital readmissions
}

\author{
Alfredo Rego ${ }^{1 *}$ (D) Patricia C. Cheung ${ }^{2}$, William J. Harris ${ }^{3}$, Kevin M. Brady ${ }^{4}$, Jeffrey Newman ${ }^{5}$ and Robert Still ${ }^{6}$
}

\begin{abstract}
Background: A prospective, multi-center study (RECON) was conducted to evaluate the clinical outcomes of pericardial closure using a decellularized extracellular matrix (ECM) graft derived from porcine small intestinal submucosa.

Methods: Patients indicated for open cardiac surgery with pericardial closure using ECM were eligible for the RECON study cohort. Postoperative complications and readmission of the RECON patients were compared to the patient cohort in the Nationwide Readmissions Database (NRD). Inverse probability of treatment weighting was used to control the differences in patient demographics, comorbidities, and risk factors.

Results: A total of 1420 patients at 42 centers were enrolled, including 923 coronary artery bypass grafting (CABG) surgeries and 436 valve surgeries. Significantly fewer valve surgery patients in the RECON cohort experienced pleural effusion $(3.1 \%$ vs. $13.0 \% ; p<0.05)$ and pericardial effusion $(1.5 \%$ vs. $2.6 \% ; p<0.05)$ than in the NRD cohort. CABG patients in the RECON cohort were less likely to suffer bleeding $(1.2 \%$ vs. $2.9 \% ; p<0.05)$ and pericardial effusion $(0.2 \%$ vs. $2.2 \%, p<0.05)$ than those in the NRD cohort. The 30-day all-cause hospital readmission rate was significantly lower among RECON patients than NRD patients following both valve surgery (HR: $0.34 ; p<0.05$ ) and CABG surgery (HR: $0.42 ; p<0.05$ ). In the RECON study, $14.4 \%$ of CABG patients and $27.0 \%$ of valve patients had postoperative atrial fibrillation as compared to previously reported risks, which generally ranges from 20 to $30 \%$ after CABG and from 35 to $50 \%$ after valve surgery.
\end{abstract}

Conclusions: Pericardial closure with ECM following cardiac surgery is associated with a reduction in the proportion of patients with pleural effusion, pericardial effusion, and 30-day readmission compared to a nationwide database.

Trial registration: NCT02073331, Registered on February 27, 2014.

Keywords: Pericardial closure, Coronary artery bypass grafting, Valve repair, Extracellular matrix, Pericardial effusion, Pleural effusion, Post-op atrial fibrillation

\footnotetext{
* Correspondence: alfredo.rego2018@gmail.com

'South Florida Heart \& Lung Institute, 3650 NW 82nd Ave, Doral, FL 33166,

USA

Full list of author information is available at the end of the article
}

(c) The Author(s). 2019 Open Access This article is distributed under the terms of the Creative Commons Attribution 4.0 International License (http://creativecommons.org/licenses/by/4.0/), which permits unrestricted use, distribution, and reproduction in any medium, provided you give appropriate credit to the original author(s) and the source, provide a link to the Creative Commons license, and indicate if changes were made. The Creative Commons Public Domain Dedication waiver (http://creativecommons.org/publicdomain/zero/1.0/) applies to the data made available in this article, unless otherwise stated. 


\section{Background}

Approximately 200,000 coronary artery bypass grafting (CABG) and 120,000 heart valve surgeries are performed each year in the USA according to the Agency for Healthcare Research and Quality (AHRQ). However, consensus among surgeons on whether or not the pericardium should be closed following these procedures is lacking, as are recommendations on the optimal method to repair the pericardium following cardiac surgery [1]. Historically, it was believed that closing the pericardium could trap blood and other fluids around the heart, thus impairing hemodynamics and leading to cardiac tamponade [2]. However, an analysis of the literature concluded that despite the temporary impacts on hemodynamics reported in some studies, there was no evidence of any adverse clinical outcome following closure of the pericardium [1]. The temporary adverse effects on hemodynamics were only observed in those cases where the pericardium was closed only using sutures, presumably causing pericardial tension [2]. Contrary to older theories predicting that pericardial closure leads to more cardiac tamponade, two clinical studies demonstrated pericardial closure actually reduced the incidence of postoperative cardiac tamponade $[3,4]$.

Closing the pericardium following initial cardiac surgery effectively reduces morbidity and mortality associated with cardiac reoperation $[1,2,5]$. Postoperative retrosternal adhesion to the heart following cardiac surgery increases the risk of myocardial injury and can cause hemorrhage during repeat sternotomies [5-8]. Closing the pericardium minimizes such adhesion by isolating the heart from the posterior table of the sternum $[2,9,10]$. Furthermore, a larger distance between the epicardial surface and the posterior table of the sternum is maintained in patients with closed pericardium following cardiac surgery as compared to the patients with open pericardium $[10,11]$.

Recent studies suggest that closing the pericardium following cardiac surgery also reduces the hospital length of stay (LOS) and postoperative complications, including postoperative atrial fibrillation (POAF) and pericardial effusion. In a retrospective study of 222 patients, Boyd et.al compared the clinical outcome of isolated CABG patients who underwent pericardial closure using porcine extracellular matrix (ECM) to patients who did not undergo pericardial closure [12]. POAF was reduced by $54 \%$ in the pericardial closure group ( $18 \%$ vs. $39 \%$ in control group). The reduction of POAF was corroborated in a randomized, controlled trial with 142 CABG patients [13], in which primary tension-free pericardial closure reduced POAF by $69 \%$. Kaya et al. [13] also demonstrated statistically significant decreases in pericardial effusion, lung infection, hospital LOS, and critical care unit LOS following pericardial closure.

Although available clinical evidence demonstrates that pericardial closure following cardiac surgery is safe and improves patient outcomes, in the United States, it is only performed in a small portion of cardiac surgeries. The clinical benefits of pericardial closure utilizing currently available technologies and optimal surgical methods has not been investigated in a large patient cohort nor in the context of current standard of care. A novel pericardial implant provides a promising solution for pericardial closure and reconstruction $[2,12]$. ProxiCor ${ }^{\text {rum }}$ (Aziyo Biologics, Inc.) is a bioresorbable, decellularized, non-crosslinked ECM graft derived from porcine small intestinal submucosa. The ECM enables easy and tension-free pericardial closure, while serving as a scaffold to facilitate pericardial regeneration and remodeling into viable, vascularized, non-fibrotic tissue similar to native pericardium [14]. The objective of the RECON study was to assess readmission rates and perioperative complications of patients undergoing CABG or valve repair and replacement after pericardial closure using ECM and compare outcomes with a national patient cohort. It is hypothesized that closure of the pericardium with ECM will reduce readmission rates and perioperative complications in patients undergoing CABG or valve repair and replacement when compared to a nationwide readmission database.

\section{Methods}

Readmission rates and clinical outcomes from a prospective, multi-center, post-market observational study at 42 U.S. medical centers (RECON cohort) were compared to discharge data from the AHRQ Healthcare Cost and Utilization Project (HCUP), 2014 National Readmission Dataset (NRD cohort) [15]. In this study, two groups of patients were studied: the isolated CABG group included patients undergoing $C A B G$ procedures without concomitant higher-risk procedures, such as valve surgery, as previously defined [16]. The valve group included patients undergoing valve repair or replacement procedures, with or without concomitant CABG procedures.

\section{RECON pericardial closure cohort}

In the RECON study cohort, all patients with pericardial closure using ECM after cardiac surgery willing to provide informed consent were eligible for enrollment in the study. There were no other inclusion or exclusion criteria defined for the study. Institutional review board approval was obtained at each center and all patients provided informed consent per national and institutional requirements. The study was registered at clinicaltrials.gov (Identifier NCT02073331).

Patients enrolled in the RECON cohort underwent open cardiac surgery followed by reconstruction of the pericardium with ECM. The ECM was approximated to the native pericardium with a running suture ensuring contact with viable tissue. A chest tube was placed internal to the pericardium in nearly all patients. At the first post-operative visit occurring approximately one 
month after surgery, data were captured on demographics and comorbidities, anticoagulation medication, perioperative complications, device-related adverse events and any surgical intervention and hospitalizations since the index procedure. Clinical outcome measures included 30-day all-cause unplanned readmission and the presence or absence of perioperative complications (atrial fibrillation (AF), cardiac tamponade, bleeding, pleural effusion, and pericardial effusion). POAF was noted on the case report form for those patients that had any notation of AF in the medical record from the time of surgery through the date of study follow-up. Bleeding broadly included all patients experiencing any bleeding complication that required intervention, such as return to the operating room. Pleural effusion was noted on the case report forms for those patients that required a thoracentesis or had imaging performed to confirm pleural effusion. Pericardial effusion was noted for those patients that experienced clinical tamponade or required pericardiocentesis.

Safety outcomes were determined by analysis of all device-related adverse events. Device-related events were defined as clinical signs, symptoms or conditions that were deemed by the investigator as causally related to the device implantation procedure, or the presence or performance of the ECM device. Events were considered device-related if, due to the temporal proximity of the adverse event to ECM device implantation, there was a reasonable possibility that the device may have caused the event or may have contributed to the severity or duration of an event caused by other means.

\section{National Readmission Database Cohort}

Clinical outcomes after pericardial closure in RECON were compared to outcomes from the NRD (2014) developed by AHRQ's HCUP. NRD contains data on all-payer inpatient stays drawn from 2048 hospitals and contains 15 million inpatient discharge records. The database sample accounts for $51.2 \%$ of the total U.S. population and $49.3 \%$ of all U.S. hospitalizations.

The cohort of isolated CABG patients was defined using the International Classification of Diseases, Ninth Revision, Clinical Modification (ICD-9-CM) procedure code. Adult patients (age $\geq 18$ years old) discharged from the hospital between January 1, 2014, and November 30, 2014 were included in this study as index events. Patients with a procedural ICD-9-CM code $36.1 \mathrm{x}$ were included in the CABG cohort, but patients with any concomitant higher risk procedure as defined in the Center for Medicare and Medicaid Service (CMS) methodology report [16] were excluded. The valve repair/replacement cohort included any patient with a valve repair or replacement ICD-9-CM code (35.1x and 35.2x). Allcause unplanned readmission was defined using the CMS unplanned readmission algorithm as the first hospital readmission within 30 days after the index event discharge date $[16,17]$. The CMS algorithm was used to exclude the planned hospitalizations including organ transplants, maintenance chemotherapy, or rehabilitations and other potentially planned procedures [16, 17].

ICD-9-CM codes were used to define presence or absence of comorbidities and risk factors, including: prior cerebrovascular accident, congestive heart failure, chronic obstructive pulmonary disease, diabetes mellitus, prior myocardial infarction, chronic renal failure, hypertension, hypercholesterolemia, smoking, and prior percutaneous coronary intervention. All primary and secondary diagnoses at admission were used to define comorbidities. Enhanced Elixhauser or Charlson coding algorithms [18] and prior literature were used to identify ICD-9-CM codes (Additional file 1: Table S1).

Besides 30-day all-cause unplanned readmissions, other outcome variables included length of stay and presence or absence of pericardial complications (cardiac tamponade, bleeding, pleural effusion, or pericardial effusion) during the initial hospital admission for surgery. These complications were defined by ICD-9-CM codes identified similarly to comorbidities described above (Additional file 1: Table S1). POAF in the NRD cohort was not assessed since the ICD-9-CM code may also be used to report the preoperative AF history of the patients.

\section{Statistical analysis}

The isolated CABG procedure group and valve procedure group were analyzed separately. For each procedure type, descriptive statistics for continuous variables, occurrences and frequencies for categorical variables, and standardized differences (difference between means/pooled standard deviation) were computed for all variables to assess whether demographics and comorbidities differed between RECON and NRD cohorts. Standardized differences are independent of sample size, and their absolute values can be interpreted as indicating a meaningful imbalance when greater than 0.1 [19].

To adjust for selection bias, stabilized inverse probability of treatment weights (IPTW) were used to account for the imbalance of baseline demographic and comorbidity variables. The propensity score using a logistic regression model was first used to estimate the probability of ECM use. All baseline demographic and comorbidity variables were included and we iteratively added and assessed the ability of demographic or comorbidity interaction terms to improve the balance of baseline covariates as indicated by covariate distributions and standardized differences (Table 1) [20]. The reciprocal of the propensity score was used to obtain IPTW and the weights were subsequently stabilized [21]. As recommended by HCUP, clustering of patients within hospitals was accounted for using 
Table 1 Demographics, comorbidities and types of procedures among RECON study cohort patients

\begin{tabular}{lll}
\hline Characteristic & \multicolumn{2}{l}{ RECON $(\mathrm{n}=1,420$ patients) } \\
\cline { 2 - 3 } & $\mathrm{n}$ & $\%$ \\
\hline Demographics & 376 & 26.48 \\
Female & 1,088 & 76.62 \\
White & 158 & 11.13 \\
Black or African American & 18 & 1.27 \\
Asian & 7 & 0.49 \\
American Indian/Alaska Native & 3 & 0.21 \\
Hawaiian or Other Pacific Islander & 146 & 10.28 \\
Other & & \\
Comorbidities and Risk Factors & 60 & 4.23 \\
Prior cerebrovascular accident & 226 & 15.92 \\
Congestive heart failure & 158 & 11.13 \\
Chronic obstructive pulmonary disease & 531 & 37.39 \\
Diabetes mellitus & 242 & 17.04 \\
Prior myocardial infarction & 70 & 4.93 \\
Chronic renal failure & 1,138 & 80.14 \\
Hypertension & 727 & 51.20 \\
Hypercholesterolemia & 357 & 25.14 \\
Smoking & 126 & 8.87 \\
Prior percutaneous coronary intervention & & \\
Index Procedure & & 65.00 \\
Isolated CABG & & 9.58 \\
CABG and Valve Repair/Replacement & 136 & 21.13 \\
Valve Repair/Replacement & & \\
Other & & \\
\hline
\end{tabular}

generalized estimating equations (GEE) and SAS PROC GENMOD [22]. Log binomial regression and GEE provided prevalence ratios (PRs) and 95\% confidence intervals (CIs) to assess differences in perioperative complications. The length of hospital stay between patients in the RECON and NRD cohorts was compared using Poisson regression and GEE.

To assess the difference in readmission rates between the RECON and NRD cohorts, an IPTW-adjusted Cox proportional hazards regression model was fit and clustered events were accounted for using a marginal approach and SAS PHREG to obtain hazard ratios (HRs). An IPTW-adjusted Cox proportional hazards regression model stratified by cohort was graphically reported. The proportional hazards assumption was assessed using time-dependent variables, goodness-of-fit testing, and log-log plots, and was not violated. For interval-censored patients (seven CABG patients, three valve patients) in the RECON cohort, the readmission was assumed to occur in the midpoint between their discharge and censor dates.
Patients were censored at the earliest of: (1) the first post-operative visit or (2) 30 days after discharge from the index admission.

All analyses were performed using SAS version 9.4 (Cary, NC). Two-sided significance was assessed at $p<0.05$.

\section{Results \\ Patient demographics and inverse probability of treatment weighting}

A total of 1420 patients were enrolled in the RECON study from 2014 to 2017. Baseline characteristics, risk factors, and surgical procedure details for these patients can be found in Table 1 . The mean \pm standard deviation age of the study cohort was $61.3 \pm 11.9$ and $26.5 \%$ were female. Only patients with isolated CABG and patients with valve repair/replacement procedures (with or without CABG) were included in the current study. Fifty-seven patients from the isolated CABG group and 44 patients from the valve repair/replacement group were excluded from the analysis due to invalid or insufficient follow-up time.

A total of 57,364 isolated CABG discharges and 42,269 valve repair/replacement discharges were identified in the NRD database from January to November 2014. The imbalances in baseline patient demographics and risk/ comorbidities observed between RECON and unadjusted NRD cohort (shown in Table 2) were weighted by IPTW. As shown in Table 3, no imbalance was observed for all comorbidities and risk factors (measured by the standardized difference $<0.1$ ), except for prior percutaneous coronary interventions (PCI) in isolated CABG patients. Patients in the RECON group had a higher proportion of previous PCI than the NRD group (22.6\% vs. $17.5 \%)$ after applying IPTW.

\section{Outcomes after heart valve repair/replacement}

Patients with pericardial closure using ECM were less likely to have pleural effusion and pericardial effusion after valve procedures. The unweighted proportions of patients with pleural effusion and pericardial effusion were 3.1 and $1.5 \%$, respectively, in the RECON group compared to 13.0 and $2.6 \%$ in the NRD group as shown in Table 4. After accounting for differences in demographics and patient comorbidities between cohorts using IPTW, the proportion of patients with pleural effusion (PR: 0.15; 95\% CI: 0.07, 0.32) and pericardial effusion (PR: 0.32; 95\% CI: 0.13, 0.77) was significantly lower among RECON patients than NRD patients.

Pericardial closure with ECM was also associated with reduced 30-day all-cause unplanned readmission following valve procedures, with 17 (4.3\%) RECON and 6096 (14.4\%) NRD patients readmitted within 30 days. After applying IPTW, RECON patients had a $66 \%$ lower risk of 30-day readmission than NRD patients (HR: 0.34; 95\% CI: 0.19, 0.61; Fig. 1). No differences in cardiac 
Table 2 Baseline demographics and comorbidities of RECON and NRD patients

\begin{tabular}{|c|c|c|c|c|c|c|c|c|c|c|}
\hline \multirow[t]{3}{*}{ Characteristic } & \multicolumn{5}{|c|}{ Valve Repair/Replacement } & \multicolumn{5}{|c|}{ Coronary Artery Bypass Graft Surgery Patients } \\
\hline & \multicolumn{2}{|c|}{$\operatorname{NRD}(n=42,269)$} & \multicolumn{2}{|c|}{$\operatorname{RECON}(n=392)$} & \multirow{2}{*}{$\begin{array}{l}\text { Standardized } \\
\text { Difference }^{a}\end{array}$} & \multicolumn{2}{|c|}{$\operatorname{NRD}(n=57,364)$} & \multicolumn{2}{|c|}{$\operatorname{RECON}(n=866)$} & \multirow{2}{*}{$\begin{array}{l}\text { Standardized } \\
\text { Difference }^{\mathrm{a}}\end{array}$} \\
\hline & $\mathrm{n}$ or Mean & $\%$ or SD & $\mathrm{n}$ or Mean & $\%$ or SD & & $\mathrm{n}$ or Mean & $\%$ or SD & $\mathrm{n}$ or Mean & $\%$ or $\mathrm{SD}$ & \\
\hline Age, mean (SD) & 66.20 & 13.47 & 62.27 & 12.87 & 0.30 & 64.92 & 10.26 & 61.68 & 10.21 & 0.32 \\
\hline Female, n (\%) & 15,995 & 37.84 & 137 & 34.95 & 0.06 & 13,584 & 23.68 & 178 & 20.55 & 0.08 \\
\hline $\begin{array}{l}\text { Prior cerebrovascular accident, } \\
\text { n (\%) }\end{array}$ & 2585 & 6.12 & 16 & 4.08 & 0.09 & 3442 & 6.00 & 31 & 3.58 & 0.11 \\
\hline Congestive heart failure, n (\%) & 17,013 & 40.25 & 101 & 25.77 & 0.31 & 12,814 & 22.34 & 83 & 9.58 & 0.35 \\
\hline $\begin{array}{l}\text { Chronic obstructive pulmonary } \\
\text { disease, } n(\%)\end{array}$ & 5251 & 12.42 & 35 & 8.93 & 0.11 & 8617 & 15.02 & 98 & 11.32 & 0.11 \\
\hline Diabetes mellitus, n (\%) & 10,990 & 26.00 & 108 & 27.55 & 0.04 & 26,169 & 45.62 & 387 & 44.69 & 0.02 \\
\hline $\begin{array}{l}\text { Prior myocardial infarction, } \\
\text { n (\%) }\end{array}$ & 2654 & 6.28 & 32 & 8.16 & 0.07 & 9323 & 16.25 & 177 & 20.44 & 0.11 \\
\hline Chronic renal failure, n (\%) & 7064 & 16.71 & 17 & 4.34 & 0.41 & 9380 & 16.35 & 39 & 4.50 & 0.40 \\
\hline Hypertension, n (\%) & 29,886 & 70.70 & 291 & 74.23 & 0.08 & 47,623 & 83.02 & 746 & 86.14 & 0.09 \\
\hline Hypercholesterolemia, n (\%) & 23,102 & 54.65 & 137 & 34.95 & 0.40 & 43,950 & 76.62 & 555 & 64.09 & 0.28 \\
\hline Smoking, n (\%) & 10,284 & 24.33 & 71 & 18.11 & 0.15 & 14,782 & 25.77 & 245 & 28.29 & 0.06 \\
\hline $\begin{array}{l}\text { Prior percutaneous coronary } \\
\text { intervention, } \mathrm{n}(\%)\end{array}$ & 3237 & 7.66 & 21 & 5.36 & 0.09 & 10,098 & 17.60 & 89 & 10.28 & 0.21 \\
\hline
\end{tabular}

\section{$S D$ standard deviation}

${ }^{a}$ Absolute value of the standardized difference $>0.1$ is considered a large imbalance

Table 3 Baseline demographics and comorbidities of RECON and NRD patients after applying IPTW

\begin{tabular}{|c|c|c|c|c|c|c|c|c|c|c|}
\hline \multirow[t]{3}{*}{ Characteristic } & \multicolumn{5}{|c|}{ Valve Replacement } & \multicolumn{5}{|c|}{ Coronary Artery Bypass Graft Surgery Patients } \\
\hline & \multicolumn{2}{|l|}{$\begin{array}{l}\text { NRD } \\
(n=42,269)\end{array}$} & \multicolumn{2}{|l|}{$\begin{array}{l}\text { RECON } \\
(n=392)\end{array}$} & \multirow[t]{2}{*}{$\begin{array}{l}\text { Standardized } \\
\text { Difference }\end{array}$} & \multicolumn{2}{|l|}{$\begin{array}{l}\text { NRD } \\
(n=57,364)\end{array}$} & \multicolumn{2}{|l|}{$\begin{array}{l}\text { RECON } \\
(n=866)\end{array}$} & \multirow[t]{2}{*}{$\begin{array}{l}\text { Standardized } \\
\text { Difference }\end{array}$} \\
\hline & n or Mean & $\%$ or SD & $\mathrm{n}$ or Mean & $\%$ or SD & & n or Mean & $\%$ or SD & $\mathrm{n}$ or Mean & $\%$ or SD & \\
\hline Age, mean (SD) & 66.16 & 13.46 & 65.68 & 13.15 & 0.04 & 64.87 & 10.27 & 64.97 & 10.04 & 0.01 \\
\hline Female, n (\%) & 15,984 & 37.81 & 148 & 38.22 & 0.01 & 13,557 & 23.63 & 207 & 23.50 & 0.00 \\
\hline $\begin{array}{l}\text { Prior cerebrovascular accident, } \\
\text { n (\%) }\end{array}$ & 2577 & 6.10 & 21 & 5.54 & 0.02 & 3421 & 5.96 & 49 & 5.58 & 0.02 \\
\hline Congestive heart failure $^{\mathrm{a}}, \mathrm{n}(\%)$ & 16,957 & 40.12 & 160 & 41.48 & 0.03 & 12,705 & 22.15 & 183 & 20.71 & 0.04 \\
\hline $\begin{array}{l}\text { Chronic obstructive pulmonary } \\
\text { disease, } \mathrm{n}(\%)\end{array}$ & 5237 & 12.39 & 46 & 11.81 & 0.02 & 8585 & 14.97 & 136 & 15.45 & 0.01 \\
\hline Diabetes mellitus, n (\%) & 10,996 & 26.01 & 88 & 22.67 & 0.08 & 26,161 & 45.61 & 394 & 44.61 & 0.02 \\
\hline $\begin{array}{l}\text { Prior myocardial infarction }{ }^{\mathrm{a}} \text {, } \\
\mathrm{n}(\%)\end{array}$ & 2661 & 6.30 & 28 & 7.26 & 0.04 & 9359 & 16.31 & 148 & 16.74 & 0.01 \\
\hline Chronic renal failure ${ }^{a}, \mathrm{n}(\%)$ & 7016 & 16.60 & 53 & 13.77 & 0.08 & 9279 & 16.18 & 143 & 16.20 & 0.00 \\
\hline Hypertension, n (\%) & 29,900 & 70.74 & 280 & 72.40 & 0.04 & 47,650 & 83.07 & 738 & 83.62 & 0.01 \\
\hline Hypercholesterolemia ${ }^{a}$, n (\%) & 23,026 & 54.47 & 212 & 54.97 & 0.01 & 43,844 & 76.43 & 711 & 80.54 & 0.10 \\
\hline Smoking, n (\%) & 10,260 & 24.27 & 87 & 22.45 & 0.04 & 14,803 & 25.81 & 213 & 24.13 & 0.04 \\
\hline $\begin{array}{l}\text { Prior percutaneous coronary } \\
\text { intervention }{ }^{\mathrm{a}}, \mathrm{n}(\%)\end{array}$ & 3228 & 7.64 & 25 & 6.42 & 0.05 & 10,036 & 17.49 & 199 & 22.56 & 0.13 \\
\hline
\end{tabular}

\section{SD standard deviation}

${ }^{a}$ Absolute value of the standardized difference $>0.1$ is considered a large imbalance 
Table 4 Prevalence of postoperative events and complications of surgery among RECON compared with NRD patients after application of IPTW to balance demographic and comorbidity variables

\begin{tabular}{|c|c|c|c|c|c|c|c|c|c|c|c|c|c|c|}
\hline \multirow[t]{3}{*}{ Outcome } & \multicolumn{6}{|c|}{ Valve Replacement } & \multicolumn{8}{|c|}{ Coronary Artery Bypass Graft Surgery Patients } \\
\hline & \multicolumn{2}{|c|}{$\begin{array}{l}\text { NRD } \\
(n=42,269)\end{array}$} & \multicolumn{2}{|c|}{$\begin{array}{l}\text { RECON } \\
(n=392)\end{array}$} & \multirow{2}{*}{$\begin{array}{l}\text { Weighted } \\
\text { Prevlaence } \\
\text { Ratio }^{a}\end{array}$} & \multirow{2}{*}{\multicolumn{2}{|c|}{$\begin{array}{l}95 \% \\
\text { Confidence } \\
\text { Interval }\end{array}$}} & \multicolumn{2}{|c|}{$\begin{array}{l}\text { NRD } 2014 \\
(n=57,364)\end{array}$} & \multicolumn{2}{|c|}{$\begin{array}{l}\text { RECON } \\
(n=866)\end{array}$} & \multirow{2}{*}{$\begin{array}{l}\text { Weighted } \\
\text { Prevalence } \\
\text { Ratio }^{a}\end{array}$} & \multirow{2}{*}{\multicolumn{2}{|c|}{$\begin{array}{l}95 \% \\
\text { Confidence } \\
\text { Interval }\end{array}$}} \\
\hline & $\begin{array}{l}\text { Crude } \\
\mathrm{n}\end{array}$ & $\begin{array}{l}\text { \% or } \\
\text { SD }\end{array}$ & $\begin{array}{l}\text { Crude } \\
\mathrm{n}\end{array}$ & $\begin{array}{l}\text { \% or } \\
\text { SD }\end{array}$ & & & & $\begin{array}{l}\text { Crude } \\
\mathrm{n}\end{array}$ & $\begin{array}{l}\text { \% or } \\
\text { SD }\end{array}$ & $\begin{array}{l}\text { Crude } \\
\text { n }\end{array}$ & $\begin{array}{l}\text { \% or } \\
\text { SD }\end{array}$ & & & \\
\hline $\begin{array}{l}\text { Length of hospital stay, } \\
\text { mean days (SD) }\end{array}$ & 10.09 & 9.41 & 9.53 & 6.18 & 1.03 & 0.93 & 1.14 & 8.77 & 6.12 & 8.12 & 5.57 & 1.05 & 0.94 & 1.17 \\
\hline Postoperative atrial fibrillation & -- & -- & 106 & 27.04 & -- & -- & -- & -- & -- & 125 & 14.43 & -- & -- & -- \\
\hline Cardiac tamponade & 427 & 1.01 & 5 & 1.28 & 0.87 & 0.29 & 2.59 & 189 & 0.33 & 0 & 0.00 & -- & -- & -- \\
\hline Bleeding & 2,213 & 5.24 & 10 & 2.55 & 0.69 & 0.35 & 1.35 & 1,688 & 2.94 & 10 & 1.15 & 0.44 & 0.24 & 0.83 \\
\hline Pleural effusion & 5,484 & 12.97 & 12 & 3.06 & 0.15 & 0.07 & 0.32 & 4,950 & 8.63 & 19 & 2.19 & 0.33 & 0.09 & 1.21 \\
\hline Pericardial effusion & 1,099 & 2.60 & 6 & 1.53 & 0.32 & 0.13 & 0.77 & 1,245 & 2.17 & 2 & 0.23 & 0.14 & 0.05 & 0.45 \\
\hline
\end{tabular}

anverse probability of treatment weighted prevalence ratio

Bold: statistically significant

tamponade, bleeding, or length of hospital stay were observed between RECON and NRD patients (hospital stay RECON: $9.5 \pm 6.2$ days; NRD: $10.1 \pm 9.4$ days).

No adverse events were deemed related to the ECM device. POAF was reported in 106 (27.0\%) valve repair/ replacement patients in the RECON group during the follow-up time period (mean 29 days).

\section{Outcomes after isolated CABG}

Patients with pericardial closure using ECM had lower bleeding and pericardial effusion after isolated CABG procedures. The unweighted proportions of patients with bleeding and pericardial effusion were 1.2 and $0.2 \%$, respectively, in the RECON group compared to 2.9 and $2.2 \%$ in the NRD group (Table 4). After applying IPTW, the prevalence of bleeding (PR: 0.44; 95\% CI: 0.24, 0.83) and pericardial effusion was significantly lower among RECON patients than NRD patients (PR: 0.14; 95\% CI: 0.05, 0.45; Table 4).

Pericardial closure using ECM was also associated with reduced 30-day all-cause unplanned readmission following isolated CABG procedures, with $29(3.3 \%)$ patients readmitted in the RECON cohort and 6427 (11.2\%) patients readmitted in the NRD cohort. After applying IPTW, the risk of 30-day readmission among RECON patients was 58\% lower than NRD patients (HR: 0.42; 95\% CI: 0.25, 0.78; Fig. 2). No differences in pleural effusion or length of stay during the index admission were observed between RECON and NRD patients (NRD: 8.8 \pm 6.1 days; RECON: $8.1 \pm 5.6$ days).

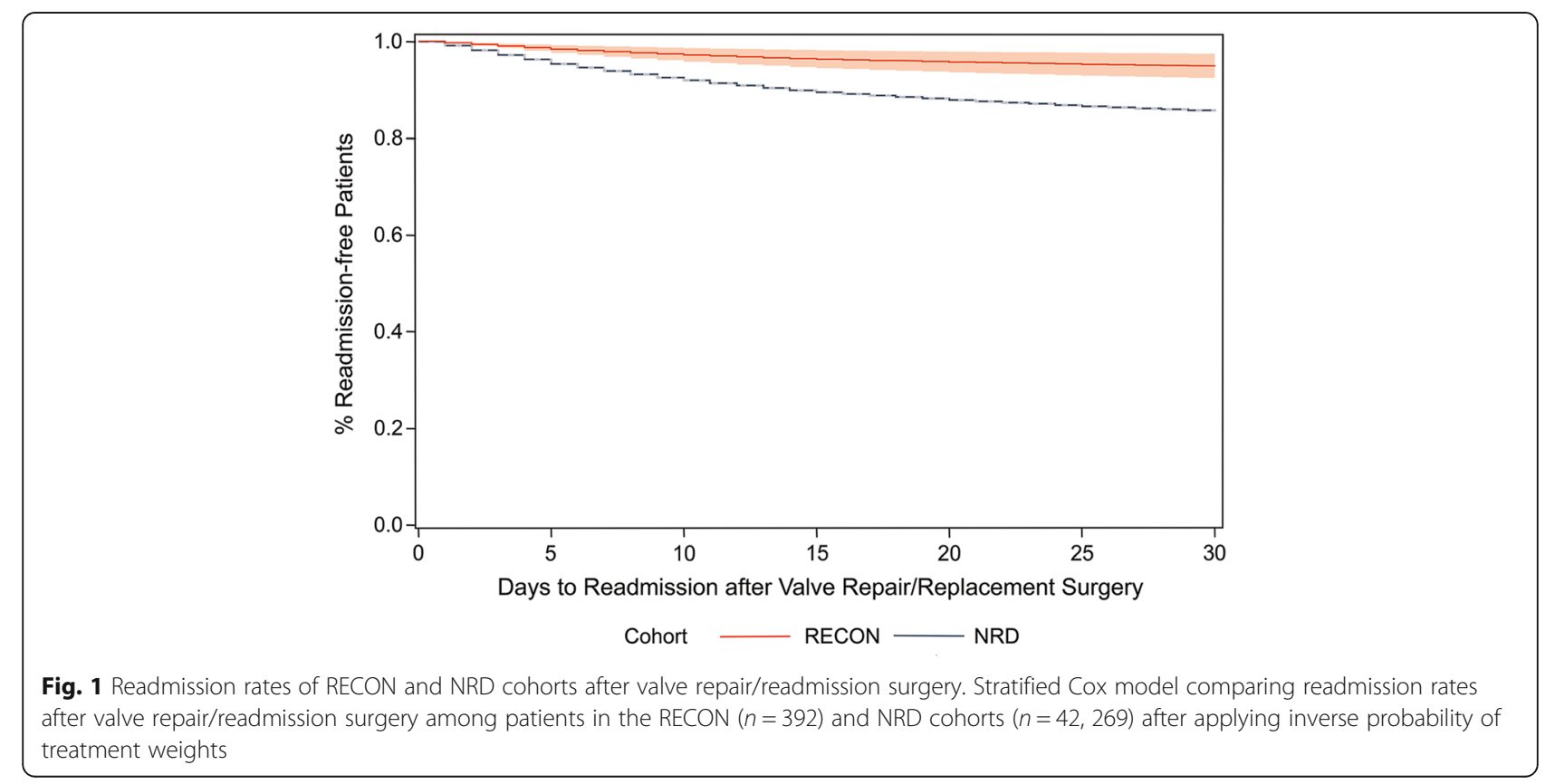




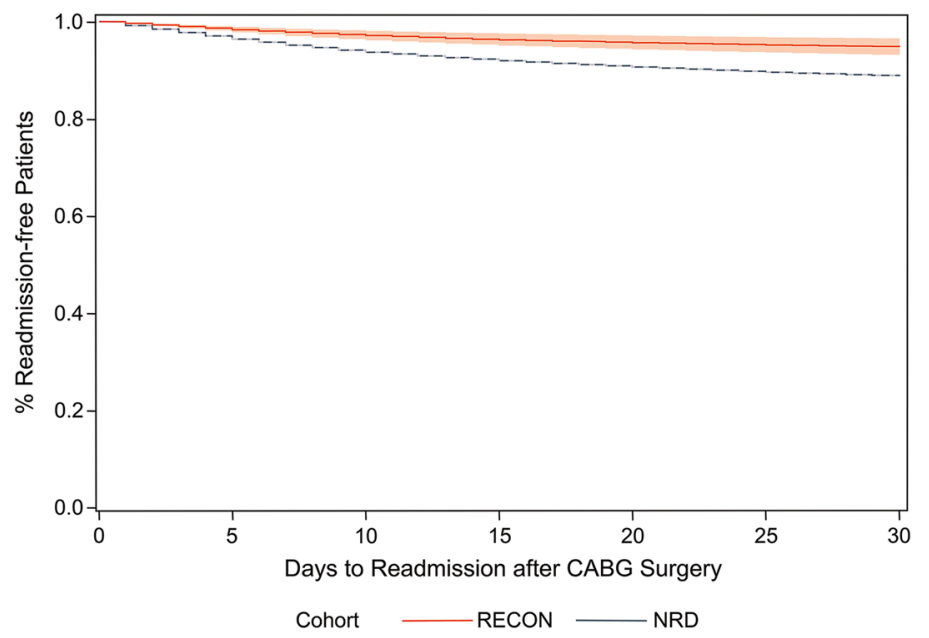

Fig. 2 Readmission rates of RECON and NRD cohorts after coronary artery bypass graft surgery. Stratified Cox model comparing readmission rates after coronary artery bypass graft surgery among patients in the RECON $(n=866)$ and NRD $(n=57,364)$ cohorts after applying inverse probability of treatment weights

No adverse events were deemed related to the implantation of the ECM. POAF was reported in 125 (14.4\%) of CABG patients in the RECON group during the follow-up time period (mean 29 days).

\section{Discussion}

A prospective, multi-center, single-arm study was conducted to assess the clinical outcomes of patients undergoing pericardial closure using ECM following cardiac surgery. A total of 1420 patients were enrolled in this study, making it likely the largest pericardial-closure patient cohort to date. The clinical outcome for 866 CABG and 392 valve repair/replacement patients in RECON was compared to the NRD with 57,364 CABG patients and 42,269 valve repair/replacement patients. IPTW were used to obtain unbiased estimates of average treatment effect of pericardial closure, controlling for patient demographics, comorbidities, and risk factors.

One of the most important findings of our study is the significant reduction in 30-day all-cause unplanned readmission rates by pericardial closure following cardiac surgery. Hospital readmission is a key measure for both patient outcome and healthcare quality. Readmission also contributes substantially to the overall healthcare cost for patients undergoing cardiac surgery. In 2007, CMS estimated the annual cost to Medicare for potentially preventable CABG readmissions was $\$ 151$ million and $\$ 8136$ per readmission [16]. Similar to prior literature, 30-day all-cause hospital readmission risks were 14 and $11 \%$ after valve procedures and isolated CABG, respectively, in the control NRD cohort [16, 23-26]. In contrast, only 4 and $3 \%$ of valve and CABG patients in the RECON group were readmitted to hospital within 30 days of the index discharge. This is the first study to report 30-day all-cause unplanned hospital readmission rates after cardiac surgery with pericardial closure. The marked reduction in hospital readmission is likely due to the reduction in multiple postoperative complications, including pericardial effusion, pleural effusion, and bleeding by pericardial closure.

New-onset AF is one of the most common postoperative complications after cardiac surgery. POAF is associated with increased cost, prolonged hospital stay, and increased morbidity and mortality $[27,28]$. In the RECON study, $14 \%$ of CABG patients and $27 \%$ of valve patients had POAF during the follow-up time period (mean 29 days). Boyd et al. [12] reported a POAF risk of $18 \%$ after CABG with pericardial closure by ECM, while Kaya et al. [13] reported 8.6\% POAF after CABG with primary pericardial closure. However, both studies had limited numbers of patients ( $n=111$ in [12] and $n=72$ in [13]), which may explain the large variability in POAF risks. The ICD-9-CM diagnosis code used in the NRD 2014 database does not distinguish POAF from pre-existing $\mathrm{AF}$, thus we were unable to compare the RECON POAF risk to the NRD control cohort. However, the proportion of patients with POAF in the RECON study are lower compared to the risks reported in the literature, which generally ranges from 20 to $30 \%$ after CABG [29-35] and from 35 to $50 \%$ after valve surgery [31, 36, 37]. Although the mechanism of POAF is not completely understood, atrial contact to shed mediastinal blood, which contains many proinflammatory cytokines and oxidative mediators, may lead to the development of POAF [38]. The ECM used to close the pericardium serves as a barrier to prevent prolonged atrial contact with mediastinal blood, and may therefore limit the proinflammatory insult to the heart and prevent POAF. 
The barrier function of ECM may also underlie the significant reduction in pericardial effusion observed in both valve and CABG patients in RECON. By re-compartmenting the heart and preventing its contact to shed mediastinal blood, the ECM could minimize pericardial inflammatory response and reduce pericardial fluid volume. This hypothesis is also supported by a recent meta-analysis conducted by Gozdek et al. [39]. It was demonstrated that posterior pericardial drainage following heart surgery markedly reduced pericardial effusion, POAF and cardiac tamponade. Posterior pericardial drainage enables unobstructed drainage of shed blood from the pericardium directly to the pleural space, thus limiting local inflammatory response. Consistent with the results observed in the RECON study, Kaya et al. [13] also observed a significantly lower incidence of pericardial effusion during the second postoperative day in patients with a closed pericardium, compared to the open pericardium group.

Pleural effusion is another common complication after cardiac surgery. The incidence of pleural effusion following CABG varies from 40 to $89 \%$ in the literature [40]. Although most of the pleural effusions are small and will resolve within 30 days without any intervention, approximately $10 \%$ of CABG patients will have a large effusion that occupies more than $25 \%$ of the hemithorax and require medical treatments $[40,41]$. The overall prevalence of pleural effusion in the patients undergoing valve surgery is lower, however more valve patients (15\%) had larger effusions [42]. The prevalence of pleural effusion in our NRD cohort was 9\% in CABG patients and $13 \%$ in valve patients. Closing the pericardium with ECM reduced the incidence of pleural effusion in patients undergoing valve surgery to $3 \%$. This reduction in pleural effusion by pericardial closure is remarkable and never reported previously. The incidence of pleural effusion in CABG patients was also decreased to $2 \%$ in patients with closed pericardium, although the reduction was not statistically significant. The mechanism for this beneficial effect of pericardial closure merits further investigation. However, since pleural effusions after cardiac surgery correlate with pericardial effusion and potential cross-talk between pericardial and pleural fluids exits [43], one might speculate that the barrier function of ECM that denies the entry of mediastinal blood to the pericardial sac may also contribute to the reduction in pleural effusion.

Consistent with previous studies, pericardial closure with ECM did not lead to any adverse clinical outcome or an increased incidence of cardiac tamponade. Only $1 \%$ of valve patients and no CABG patient in the RECON group reported cardiac tamponade. The prevalence of cardiac tamponade reported in our study are lower than the values reported in the literature $(0-1 \%$ after isolated CABG and approximately $4 \%$ after valve procedures [44-49]).

\section{Limitations}

There were three limitations of note in this study. First, ECM use was not randomized, which increases the possibility of unmeasured or residual confounding. Further, some comorbidities were not available in the NRD data due to its data structure and were not included in the propensity score mode. However, the comparability of available demographic and patient comorbidities between the two cohorts was maximized using IPTW. Second, while comorbidities and outcomes were defined by ICD-9-CM codes in the NRD cohort, these data were captured by a case report form in the RECON cohort. Different methods in data acquisition may have resulted in exposure and outcome misclassification bias, although bias was likely non-differential. Third, it was assumed that the readmission date for the ten interval-censored RECON patients occurred halfway between the dates of discharge and censorship, which may have led to mismeasurement of readmission. However, sensitivity analyses assuming either (1) readmission occurring on the day after discharge or (2) readmission occurring on the day of censorship did not affect the magnitude, direction, or significance of the HR estimate.

Furthermore, the limited sample size in the RECON valve repair/replacement cohort prevented further patient stratification into valve repair and replacement sub-groups. Valve replacement and repair have different operation techniques and risk levels, thus the effect of pericardial closure might be different in these two group. Further study is necessary to study the outcome of pericardial closure in these sub-groups.

It is also important to reiterate that the data in the present study include outcomes from patients treated in the United States only. Although pericardial closure following cardiac surgery is not standard of care in the United States, this surgical practice is more common in other countries. As a result, complication rates presented in the NRD may differ from those rates of other countries.

\section{Conclusions}

In conclusion, this study demonstrated that pericardial closure using ECM following cardiac surgery is associated with a reduction in 30-day all-cause readmission and postoperative complications including pericardial effusion, pleural effusion, and bleeding without any observed negative impact on patient safety.

\section{Additional file}

Additional file 1: Table S1. Comorbidities and perioperative outcomes obtained from the National Readmission Database 2014 and categorized according to enhanced Elixhauser or Charlson coding algorithms, other prior literature, or clinical expertise. (DOCX $21 \mathrm{~kb}$ ) 


\section{Abbreviations}

CABG: Coronary artery bypass grafting; ECM: Extracellular matrix; HR: Hazard Ratio; IPTW: Inverse probability of treatment weighting; NRD: Nationwide Readmissions Database; POAF: Postoperative atrial fibrillation; PR: Prevalence Ratio

\section{Acknowledgements}

Not applicable.

\section{Funding}

The clinical trial was sponsored by Aziyo Biologics, Inc.

\section{Availability of data and materials}

The datasets analyzed during the current study may be available from the corresponding author on reasonable request.

\section{Authors' contributions}

AR assisted with study design, collected, analyzed and interpreted study data and drafted and revised manuscript sections. PC analyzed and interpreted study data and drafted and revised manuscript sections. WH, KB, JN and RS collected and interpreted study data and revised manuscript sections. All authors read and approved the final manuscript.

\section{Ethics approval and consent to participate}

Ethics/Institutional review board approval was obtained through Western Institutional Review Board (WIRB Protocol \# 20140138) and also with those local institutional review boards at participating centers as required. Participating patients provided informed consent per national and institutional requirements.

\section{Consent for publication}

Not applicable.

\section{Competing interests}

A. rego, W. Harris, J. Newman and P. Cheung served as consultants to Aziyo Biologics, Inc. The authors have no other relevant affiliations or financial conflict with the subject matter or materials discussed in the manuscript apart from those disclosed.

\section{Publisher's Note}

Springer Nature remains neutral with regard to jurisdictional claims in published maps and institutional affiliations.

\section{Author details}

${ }^{1}$ South Florida Heart \& Lung Institute, 3650 NW 82nd Ave, Doral, FL 33166, USA. ${ }^{2}$ Department of Epidemiology, Emory University Rollins School of Public Health, Atlanta, GA, USA. ${ }^{3}$ Baptist Health Systems, Jackson, MS, USA. ${ }^{4}$ Southwest Heart and Lung, Phoenix, AZ, USA. ${ }^{5}$ Tenet Health Care, Delray Beach, FL, USA. ${ }^{6}$ Baptist Health, Jacksonville, FL, USA.

\section{Received: 14 December 2018 Accepted: 17 February 2019} Published online: 15 March 2019

\section{References}

1. Bittar MN, Barnard JB, Khasati N, Richardson S. Should the pericardium be closed in patients undergoing cardiac surgery. Interact Cardiovasc Thorac Surg [Internet]. 2005;4(2):151-5 Available from: http://www.ncbi.nlm.nih.gov/ pubmed/17670379.

2. Boyd WD, Tyberg $\mathrm{JV}$, Cox $\lrcorner$. A review of the current status of pericardial closure following cardiac surgery. Expert Rev Cardiovasc Ther [Internet]. 2012;10(9):1109-18 Available from: https://www.tandfonline.com/doi/full/10. 1586/erc.12.87.

3. Nandi P, Leung JS, Cheung KL. Closure of pericardium after open heart surgery. A way to prevent postoperative cardiac tamponade. Br Heart J. 1976;38(12):1319-23.

4. Cunningham JN, Spencer FC, Zeff R, Williams CD, Cukingnan R, Mullin M. Influence of primary closure of the pericardium after open-heart surgery on the frequency of tamponade, postcardiotomy syndrome, and pulmonary complications. J Thorac Cardiovasc Surg [Internet]. 1975;70(1):119-25 Available from: http://europepmc.org/abstract/MED/1152493.
5. Dobell ARC, Jain AK. Catastrophic hemorrhage during redo sternotomy. Ann Thorac Surg. 1984;37(4):273-8.

6. Roselli EE, Pettersson GB, Blackstone EH, Brizzio ME, Houghtaling PL, Hauck $R$, et al. Adverse events during reoperative cardiac surgery: frequency, characterization, and rescue. J Thorac Cardiovasc Surg. 2008;135(2):316-23.

7. Gazzaniga $A B$, Palafox BA. Substernal thoracoscopic guidance during sternal reentry. Ann Thorac Surg. 2001;72(1):289-90.

8. Loop FD. Catastrophic hemorrhage during sternal reentry. Ann Thorac Surg. 1984;37(4):271-2.

9. Gallo I, Artiñano E, Duran CG. Late clinical results with the use of heterologous pericardium for closure of the pericardial cavity. J Thorac Cardiovasc Surg [Internet]. 1985;89(5):709-12 Available from: http:// europepmc.org/abstract/MED/3990321.

10. Rao V, Komeda M, Weisel RD, Cohen G, Borger MA, David TE. Should the pericardium be closed routinely after heart operations? Ann Thorac Surg. 1999;67(2):484-8.

11. Lahtinen J, Satta J, Lähde S, Suramo I, Nissinen J, Pokela R, et al. Computed tomographic evaluation of retrosternal adhesions after pericardial substitution. In: Annals of thoracic surgery; 1998. p. 1264-8.

12. Boyd WD, Johnson WE, Sultan PK, Deering TF, Matheny RG. Pericardial reconstruction using an extracellular matrix implant correlates with reduced risk of postoperative atrial fibrillation in coronary artery bypass surgery patients. Heart Surg Forum [Internet]. 2010;13(5):E311-6 Available from: http://www.ncbi.nlm.nih.gov/pubmed/20961831.

13. Kaya M, Satilmisoglu MH, Bugra AK, Kyaruzi M, Kafa U, Utkusavas A, et al. Impact of the total pericardial closure using bilateral trap door incision and pericardial cavity intervention on outcomes following coronary artery bypass grafting: a randomized, controlled, parallel-group prospective study. Interact Cardiovasc Thorac Surg. 2015;21(6):727-33.

14. Brown BN, Badylak SF. Extracellular matrix as an inductive scaffold for functional tissue reconstruction. Transl Res [Internet]. 2014;163(4):268-85 Available from: https://doi.org/10.1016/j.trsl.2013.11.003.

15. HCUP Agency for Healthcare Research and Quality, Rockville M. Introduction To The Hcup Nationwide Readmissions Database (Nrd) 2014. 2017.

16. Araas M, Joyce E, Potteiger J. Hospital-level 30-day all-cause unplanned readmission following coronary artery bypass graft surgery ( $C A B G$ ) updated measure methodology report. Centers Medicare Medicaid Serv 2014;2014.

17. Horwitz LI, Grady JN, Cohen DB, Lin Z, Volpe M, Ngo CK, et al. Development and validation of an algorithm to identify planned readmissions from claims data. J Hosp Med. 2015;10(10):670-7.

18. Quan H, Sundararajan V, Halfon P, Fong A, Burnand B, Luthi J-C, et al. Coding Algorithms for Defining Comorbidities in ICD-9-CM and ICD-10 Administrative Data. Med Care [Internet]. 2005;43(11):1130-9 Available from: https://www.ncbi.nlm.nih.gov/pubmed/16224307.

19. Normand S-LT, Landrum MB, Guadagnoli E, Ayanian JZ, Ryan TJ, Cleary PD, et al. Validating recommendations for coronary angiography following acute myocardial infarction in the elderly: a matched analysis using propensity scores. J Clin Epidemiol. 2001;54(4):387-98.

20. Austin PC. An Introduction to propensity score methods for reducing the effects of confounding in observational studies. Multivariate Behav Res [Internet]. 2011;46(3):399-424 Available from: http://www.tandfonline.com/ doi/abs/10.1080/00273171.2011.568786.

21. Austin PC, Stuart EA. Moving towards best practice when using inverse probability of treatment weighting (IPTW) using the propensity score to estimate causal treatment effects in observational studies. Stat Med. 2015; 34(28):3661-79.

22. Houchens R, Chu B, Steiner C. Hierarchical modeling using HCUP data HCUP methods series report \# 2007-01; 2007.

23. D'Agostino RS, Jacobson J, Clarkson M, Svensson LG, Williamson C, Shahian DM. Readmission After Cardiac Operations: Prevalence, Patterns, And Predisposing Factors. J Thorac Cardiovasc Surg. 1999;118:823-32.

24. Goodney PP, Stukel TA, Lucas FL, Finlayson EVA, Birkmeyer JD. Hospital volume, length of stay, and readmission rates in high-risk surgery. Ann Surg. 2003:238(2):161-7

25. Stewart RD, Campos CT, Jennings B, Lollis SS, Levitsky S, Lahey SJ. Predictors of 30-day hospital readmission after coronary artery bypass. Ann Thorac Surg. 2000;70(1):169-74.

26. Hannan EL, Zhong Y, Lahey SJ, Culliford AT, Gold JP, Smith CR, et al. 30-Day readmissions after coronary artery bypass graft surgery in New York State. JACC Cardiovasc Interv [Internet]. 2011:4(5):569-76 Available from: https://doi.org/10.1016/j.jcin.2011.01.010. 
27. Hu X, Chen Y, Zhou Z, Ying J, Hu Y, Xu G. Posterior pericardiotomy for the prevention of atrial fibrillation after coronary artery bypass grafting: A metaanalysis of randomized controlled trials. Int J Cardiol [Internet]. 2016;215: 252-6 Available from: http://linkinghub.elsevier.com/retrieve/pii/ S0167527316307562

28. Tran DTT, Perry JJ, Dupuis J-Y, Elmestekawy E, Wells GA. Predicting newonset postoperative atrial fibrillation in cardiac surgery patients. J Cardiothorac Vasc Anesth [Internet]. 2015;29(5):1117-26 Available from: http://www.sciencedirect.com/science/article/pii/S105307701400648X.

29. Kaleda VI, McCormack DJ, Shipolini AR. Does posterior pericardiotomy reduce the incidence of atrial fibrillation after coronary artery bypass grafting surgery? Interact Cardiovasc Thorac Surg. 2012;14(4):384-9.

30. Saxena A, Dinh DT, Smith JA, Shardey GC, Reid CM, Newcomb AE. Usefulness of postoperative atrial fibrillation as an independent predictor for worse early and late outcomes after isolated coronary artery bypass grafting (multicenter australian study of 19,497 patients). Am J Cardiol [Internet]. 2012;109(2):219-25 Available from: https://doi. org/10.1016/j.amjcard.2011.08.033.

31. Rostagno C, La Meir M, Gelsomino S, Ghilli L, Rossi A, Carone E, et al. Atrial fibrillation after cardiac surgery: Incidence, risk factors, and economic burden. J Cardiothorac Vasc Anesth [Internet]. 2010;24(6):952-8 Available from: https://doi.org/10.1053/j.jvca.2010.03.009.

32. Filardo G, Hamilton C, Hebeler RF, Hamman B, Grayburn P. New-onset postoperative atrial fibrillation after isolated coronary artery bypass graft surgery and long-term survival. Circ Cardiovasc Qual Outcomes. 2009;2(3): 164-9.

33. Aranki SF, Shaw DP, Adams DH, Rizzo RJ, Couper GS, VanderVliet M, et al. Predictors of Atrial Fibrillation After Coronary Artery Surgery: Current Trends and Impact on Hospital Resources. Circulation [Internet]. 1996;94(3):390-7 Available from: http://circ.ahajournals.org/cgi/doi/10.1161/01.CIR.94.3.390.

34. Mathew JP. A Multicenter Risk Index for Atrial Fibrillation After Cardiac Surgery. Jama [Internet]. 2004;291(14):1720 Available from: http://jama. jamanetwork.com/article.aspx?doi=10.1001/jama.291.14.1720.

35. El-Chami MF, Kilgo P, Thourani V, Lattouf OM, Delurgio DB, Guyton RA, et al. New-onset atrial fibrillation predicts long-term mortality after coronary artery bypass graft. J Am Coll Cardiol. 2010;55(13):1370-6.

36. Helgadottir S, Sigurdsson MI, Ingvarsdottir IL, Amar DO, Gudbjartsson T. Atrial fibrillation following cardiac surgery: risk analysis and long-term survival. J Cardiothorac Surg [Internet]. 2012;7(1):87-93. Available from: https://www.ncbi.nlm.nih.gov/pubmed/22992266.

37. Shen J, Lall S, Zheng V, Buckley P, Damiano RJ, Schuessler RB. The persistent problem of new-onset postoperative atrial fibrillation: a single-institution experience over two decades. J Thorac Cardiovasc Surg. 2011;141(2):559-70.

38. St-Onge S, Perrault LP, Demers P, Boyle EM, Gillinov AM, Cox J, et al. Pericardial Blood as a Trigger for Postoperative Atrial Fibrillation After Cardiac Surgery. Ann Thorac Surg [Internet]. 2017;105(1):321-8 Available from: https://doi.org/10.1016/j.athoracsur.2017.07.045

39. Gozdek M, Pawliszak W, Hagner W, Zalewski P, Kowalewski J, Paparella D, et al. Systematic review and meta-analysis of randomized controlled trials assessing safety and efficacy of posterior pericardial drainage in patients undergoing heart surgery. J Thorac Cardiovasc Surg [Internet]. 2016;153(4): 85-94 Available from: http://www.ncbi.nlm.nih.gov/pubmed/28087110.

40. Light RW. Pleural Diseases - 6th ed. Philadelphia: Lippincott Williams \& Wilkins; 2013. p. 459-61.

41. Light RW. Pleural effusions after coronary artery bypass graft surgery. Curr Opin Pulm Med [Internet]. 2002;8(4):308-11 Available from: http://eutils.ncbi. nlm.nih.gov/entrez/eutils/elink.fcgi?dbfrom=pubmed\&amp;id= 12055394\&amp;retmode=ref\&amp;cmd=prlinks.

42. Light RW, Rogers JT, Moyers JP, Lee YCG, Rodriguez RM, Alford WC, et al. Prevalence and Clinical Course of Pleural Effusions at 30 Days after Coronary Artery and Cardiac Surgery. Am J Respir Crit Care Med [Internet]. 2002; 166(12):1567-71 Available from: http://www.atsjournals.org/doi/abs/10.1164/ rccm.200203-1840C.

43. Vargas FS, Cukier A, Hueb W, Teixeira LR, Light RW. Relationship between pleural effusion and pericardial involvement after myocardial revascularization. Chest [Internet]. 1994;105(6):1748-52 Available from: https://doi.org/10.1378/chest.105.6.1748.

44. Kuvin JT, Harati NA, Pandian NG, Bojar RM, Khabbaz KR. Postoperative cardiac tamponade in the modern surgical era. Ann Thorac Surg. 2002;74(4): 1148-53.
45. Martins EF, Heemann A, Neto P, Danielli L, Nunes LA, Vitória M, et al. Incidence And Factors Associated With Pericardial Effusion After Cardiac Valve Surgery. Clin Biomed Res. 2017:18-24.

46. Khan NK, Järvelä KM, Loisa EL, Sutinen JA, Laurikka JO, Khan JA. Incidence, presentation and risk factors of late postoperative pericardial effusions requiring invasive treatment after cardiac surgery. Interact Cardiovasc Thorac Surg. 2017;24(6):835-40.

47. You SC, Shim CY, Hong G-R, Kim D, Cho IJ, Lee S, et al. Incidence, predictors, and clinical outcomes of postoperative cardiac tamponade in patients undergoing heart valve surgery. PLoS One [Internet]. 2016;1 1(11): e0165754 Available from: http://dx.plos.org/10.1371/journal.pone.0165754.

48. Meurin P, Weber H, Renaud N, Larrazet F, Tabet JY, Demolis P, et al. Evolution of the postoperative pericardial effusion after day 15: the problem of the late tamponade. Chest. 2004;125(6):2182-7.

49. Zhao J, Cheng Z, Quan X, Zhao Z. Does posterior pericardial window technique prevent pericardial tamponade after cardiac surgery? J Int Med Res [Internet]. 2014;42(2):416-26. Available from: https://www.ncbi.nlm.nih. gov/pubmed/24553479.

\section{Ready to submit your research? Choose BMC and benefit from:}

- fast, convenient online submission

- thorough peer review by experienced researchers in your field

- rapid publication on acceptance

- support for research data, including large and complex data types

- gold Open Access which fosters wider collaboration and increased citations

- maximum visibility for your research: over $100 \mathrm{M}$ website views per year

At BMC, research is always in progress.

Learn more biomedcentral.com/submissions 